\title{
Representación política en un contexto de transición. Análisis del caso de Raúl Porras Barrenechea como senador en el Congreso Peruano (1956-1958) ${ }^{1}$
}

\section{Political representation in a context of transition. Analysis of the case of Raúl Porras Barrenechea as senator in the Peruvian Congress (1956-1958)}

\section{Carlota Casalino ${ }^{2}$}

\section{Resumen}

La transición política peruana de 1956 permitió que senadores como Raúl Porras Barrenechea dieran mayor importancia a la función de representación que a otras funciones propias de los parlamentarios, como el control político, la iniciativa legislativa y la deliberación. La explicación a esa preferencia radica en la necesidad de democratizar una sociedad que du-

1 Artículo desarrollado en el marco del proyecto E20151741-VRIPUNMSM.

2 Profesora principal de la UNMSM, investigadora Renacyt-Concytec, doctora en ciencias sociales (UNMSM), magíster en historia (PUCP) y licenciada y bachiller en historia (UNMSM). Especializada en educación para el desarrollo y en ciencia política (PUCP), así como en la gestión de proyectos (PUCP) y monitoreo y evaluación de proyectos (ESAN). Correspondencia (Corresponding autor): ccasalinos@ unmsm.edu.pe Código ORCID: 0000-0002-3102-8925 
rante el gobierno anterior de Manuel A. Odría -el ochenio autoritario- había interrumpido la mediación entre el parlamento y la sociedad, y en su lugar había generado relaciones patrón-cliente entre una población despolitizada y el líder a cargo del Poder Ejecutivo. De ahí que privilegiar la función de representación era contribuir a promover la ciudadanía y la canalización de las demandas a través del Parlamento.

Palabras clave: Perú, siglo XX, transición política, Congreso peruano, representación política, Raúl Porras Barrenechea

\section{Abstract}

The Peruvian political transition of 1956 allowed senators like Raúl Porras Barrenechea to give more importance to the function of political representation than to other parliamentarian's functions, such as political control, legislative issues and deliberation. The explanation for this preference lies in the need to democratize a society that during the previous government of Manuel A. Odría -the authoritarian period of eight years- had interrupted the mediation between parliament and society, and instead had generated patron-client relations between a depoliticized population and the leader in charge of the Executive Power. Hence, privileging the function of representation meant contributing to the promotion of citizenship and the channeling of demands through Parliament.

Key words: Peru, 20th century, political transition, Peruvian

200 Congress, political representation, Raúl Porras Barrenechea

\section{Introducción}

La historia política del Perú del siglo XX se caracteriza por el predominio de gobiernos autoritario-oligárquicos con breves momentos democratizadores. En ese contexto, el Parlamen- 
to peruano ha tenido un rol particular en su relación con el Poder Ejecutivo y con la sociedad. Por ejemplo, a finales de la segunda década del siglo XXI, el Perú tuvo un gobierno dividido, el Ejecutivo no tenía mayoría en el Parlamento, había tensión entre ambos y el Congreso tenía poca aceptación de la opinión pública. Ello, dio lugar a su disolución y a la convocatoria a elecciones congresales extraordinarias. Sin embargo, considero que esa percepción negativa no solo expresa una crisis de representación. Pudo ser la punta de un iceberg de problemas mayores y más complejos. Cuando en el siglo anterior tuvimos el mismo fenómeno de gobiernos divididos, generalmente los gobiernos de entonces no culminaron el periodo para el que fueron elegidos porque se produjeron golpes de Estado, como en los periodos 1945-1948 y $1963-1968$.

Al respecto, los estudios sobre el Parlamento en general y el caso peruano en particular, han sido abordados por diversas disciplinas, como la historia (Abanto, 2017; Basadre, 1980; Macera, 2020; Manin, 2008; Pérez Garay, 2015; Poulsen, 2018; Ragas y Gálvez, 2010; Rosanvallon, 2010,), el derecho parlamentario y constitucional (Bernales 1970, 1981, 1984, 1990, 2001, 2009; Delgado Guembes, 2011; Jiménez, 1994; Landa, 1994; Schmitt [1923], 2008) y la ciencia política (Abal, 2004; Aragón, 2016; Benito, 2017; Córdoba, 2017; Gargarella, 2010; Máiz, 2006; Pease, 2006; Pérez, 2009; Przeworski, 2019; Rebata, 2015; Sánchez, Nolte y Llanos, 2005; Tuesta, 2005), entre otros, que analizan las instituciones, sus interrelaciones, periodos, características, funciones, composición y otros temas. Respecto a los estudios sobre los representantes peruanos, hay algunos que destacan las principales intervenciones políticas (Ayllón, 2019; Casalino, 1997; Chang-Rodríguez, 2003; Flores-Zúñiga, 2019; Lecaros, 2007; Nugent, 2013) o una interpretación de su labor político-parlamentaria (Guerra, 2016; Padilla, 2018; Varillas, 2019; Villanueva, 2016; Wa- 
tanabe, 2017). Finalmente, hay estudios sobre el papel de los intelectuales que pensaron en los problemas del país y buscaron caminos de solución, entre ellos, el incursionar en la actividad política e incluso partidaria (Aguilar y Rojas, 2002; Aguirre y Mc Evoy, 2008; Altamirano, 2010; Deustua y Rénique, 1984; Heilman, 2018; Moore, 2018; Myers, 2008; Rama, 2004; Rénique, 2015 y 2016; Rojas, 2017; Wilson, 2018).

Sobre la base de lo señalado, considero que se requiere profundizar el análisis de las funciones del parlamento -especialmente del Senado- y la manera como eran practicadas por los representantes. Por lo tanto, se puede ilustrar ese acercamiento a través de un caso que permite conocer la labor parlamentaria a partir de las funciones establecidas para los representantes políticos. Para ilustrarlo, he seleccionado como objeto de estudio a Raúl Porras Barrenechea (RPB) (1897-1960) en su breve paso como Senador de la República del Perú entre 1956 y 1958. En efecto, bastaron alrededor de tres años en el Senado - de los seis que duraba el mandato- para dejar una huella imborrable. Ello se expresa, por ejemplo, en el imponente retrato de cuerpo entero en la sala RPB del Congreso, con el que se reconoce su importancia como arquetipo de senador, su proyección y su influencia política.

Su presencia en el Congreso se caracterizó por una profunda vocación de servicio y participación en los procesos de deliberación y confrontación de ideas en el hemiciclo para abordar los diversos problemas. Su labor parlamentaria, conformada por proyectos de ley, mociones de orden del día, pedidos, dictámenes, proyectos sustitutorios e intervenciones en las sesiones plenarias fue -algunas veces- una voz aislada, pero potente. Otras veces, logró persuadir a miembros de otras bancadas para que se adhirieran a sus propuestas. De igual manera, suscribió propuestas de otros -no solo de su 
propia bancada- sino de casi todas las bancadas de entonces. Demostró con ello una actitud plural cuando está de por medio el bien común y que en el proceso de deliberación es posible arribar a acuerdos.

En el contexto de la mitad del siglo XX, el Perú protagonizó cambios generados por factores internos y externos, que prácticamente dieron lugar al Perú de las siguientes décadas. En la política destacan dos hechos clave: por primera vez las mujeres ejercieron su derecho al sufragio (activo y pasivo). En efecto, la ley N. ${ }^{\circ} 12391$ (7/sep/1955) dispuso el voto para las mujeres alfabetas; resultado de ello fue que de 4,485,763 mujeres en 1956 fueron a sufragar 531,541 y llegaron a ser elegidas representantes una senadora y siete diputadas. El segundo hecho clave produjo la «convivencia», cuando el PAP, un partido político popular surgido en la década de 1920 giró hacia la derecha y estableció un pacto de gobernabilidad con sectores conservadores, como el pradismo y el odrí́smo, con el fin de obtener legalidad y entrar a la esfera política y al sistema de partidos (López, 2018; Pease y Romero, 2015).

En el siguiente gráfico, se aprecia el efecto en la curva por la participación de mujeres en el proceso electoral de 1956. Si bien en 1980, cuando se dio el voto a la población analfabeta, hubo una mayor tendencia, es claro el efecto que significó la participación femenina en el proceso de 1956. 
Figura 1. Porcentaje de electores respecto a la población estimada, 1931-2016

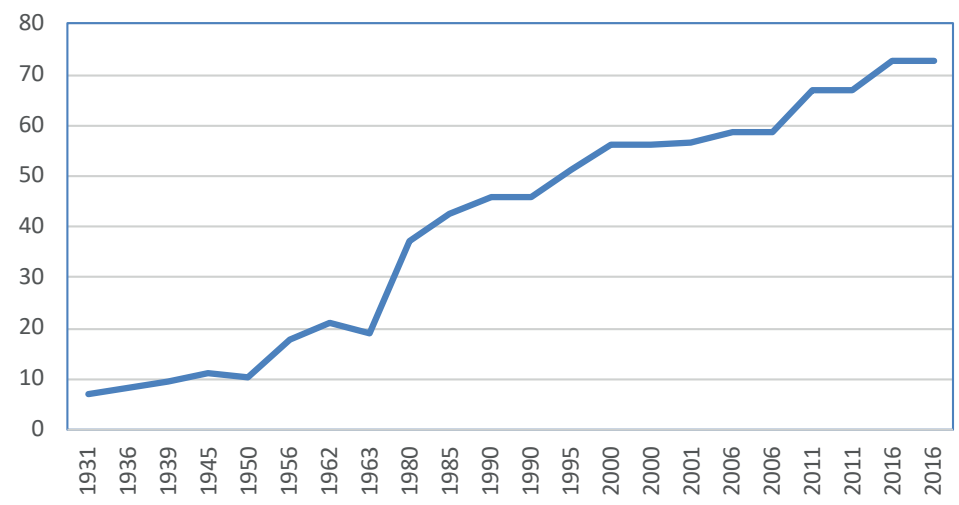

Fuente: Elaboración propia basada en Rebata (2015).

Sostengo que en ese contexto de cambios con inclusión de las mujeres alfabetas a la ciudadanía y de transición de un régimen autoritario como el ochenio de Odría a uno oligárquico como el segundo gobierno de Manuel Prado Ugarteche, nuestro personaje desplegó mucho más su labor de representación, que otras funciones propias de un senador, como el control político, la deliberación o la iniciativa legislativa. Si bien estas también las ejerció, dio preferencia a la función de representación, especialmente de los grupos sociales y de la población de Lima provincias, porque el gobierno saliente, por sus propias características autoritarias había distorsiona-

204 do la canalización de demandas de la sociedad hacia la esfera política. Entonces, recuperar la relación Estado-sociedad a través de la mediación parlamentaria en la esfera política fue una tarea desarrollada por RPB, Senador por Lima, quien como parte de una lista independiente obtuvo la segunda votación más alta de todos los candidatos al Congreso.

Antes de analizar su labor parlamentaria, es conveniente presentarlo en unas breves líneas. RPB aportó a la compren- 
sión y conocimiento de la crítica literaria, historia, derecho y diplomacia. Fue maestro de escuela y de la Universidad Nacional Mayor de San Marcos. Participó activamente en los asuntos públicos, tanto universitarios como de la sociedad, y fue elegido senador para el periodo 1956-1962. Nació en Pisco el 23 de marzo de 1897 y era bisnieto del prócer José María Raygada, cuyos restos yacen en el Panteón de los Próceres de la Nación. Su abuelo fue ministro de Relaciones Exteriores. Desde la escuela, en La Recoleta, ya escribía en el boletín, luego estudió en San Marcos en la Facultad de Letras de 1912 a 1915 y en la Facultad de Derecho de 1915 a 1920. En 1928 obtuvo el doctorado en filosofía, historia y letras. Tuvo una intensa actividad en el Conversatorio Universitario, celebraciones académicas en torno al centenario de la Independencia y en la reforma universitaria de 1919 y 1930. Desde muy joven ingresó al servicio público en el Ministerio de Relaciones Exteriores, actividad que compartió con la cátedra en San Marcos. El último lustro de su vida fue clave, pues fue candidato a rector de San Marcos, fue elegido senador por Lima y ministro de Relaciones Exteriores. Falleció en 1960 en su casa en Miraflores. Sus funerales expresaron ese rasgo principal de persona polifacética y apasionada por el Perú, todos los grupos a los que perteneció lo reclamaron para sí: sus alumnos y discípulos de La Recoleta, de San Marcos, de la Academia Diplomática, el Ministerio de Relaciones Exteriores y el Senado de la República.

\section{Raúl Porras Barrenechea, pensar y representar en un contexto de transición política}

La unicameralidad del congreso peruano actual es producto de la Constitución de 1993. Antes de ello, había sido bicameral con un Senado y una Cámara de Diputados. Por ello, empezaré este acápite describiendo las funciones del Senado. Sánchez, Nolte y Llanos (2005) sostienen que tanto el derecho constitucional como la teoría política establecen teóri- 
camente cuatro justificaciones para la existencia de una Cámara Alta: (1) Con dos cámaras se puede organizar mejor la representación de distintos intereses. (2) Es una contribución al sistema de pesos y contrapesos. (3) Se logra una mejor calidad legislativa. (4) Se puede producir resultados legislativos más estables (pp. 18-20). Considero que hay una quinta, con la lógica del todo y de la parte, que consiste en que mientras en Diputados se pueden canalizar los intereses de lo local, en el Senado se pueden canalizar los intereses nacionales. Asimismo, sucede que para la Cámara Alta suelen candidatear y ser elegidos legisladores con más experiencia, de ahí que se considera una instancia reflexiva conformada por un número menor de escaños. En ese sentido, Bernales (2017) sostiene que la existencia de un Senado contribuye a una mejor distribución de los distritos electorales, lo que da el peso que corresponde a la función principal, que es la representación. Finalmente, es en esta donde se reflexionan y debaten los problemas estructurales del país y su visión de futuro, por lo que es la fuente principal de la formación ciudadana.

El Congreso al que se incorporó Porras marcó un hito en su historia, pues al tratarse de un periodo de transición, necesariamente aumentó su peso político respecto al régimen anterior, el ochenio, al adquirir mayor autonomía del Ejecutivo. Además, fue un parlamento con mayor legitimidad al haberse incrementado significativamente el número de electores por el voto de las mujeres y los hombres alfabetos (Shüttemeyer y Nohlen, 2006, pp. 999-1000). El propio Congreso lo expresó así al consignar el periodo 1956-1978 como «democracia mixta alfabeta» al introducirse los efectos de la Declaración Universal de los Derechos Humanos y las nuevas tendencias sobre derechos y deberes de ambos sexos (Congreso de la República: página web, 2019). Recordemos que el contexto internacional se enmarca en la etapa conocida como post Segunda Guerra Mundial. Es decir, cuando se abrieron varios procesos paralelos complejos e interrela- 
cionados, como la conformación de la ONU, el proceso de erradicación del nazismo, la democratización de Alemania y Japón, el plan Marshall y el plan Comecon, la guerra fría y la descolonización (Gaddis, 2011; Powaski, 2011). Ese contexto internacional fue importante, pues dada la especialización de RPB en relaciones exteriores, su labor estuvo orientada a señalar los principios que debía mantener el Perú frente al escenario internacional.

Nuestro personaje fue elegido senador por Lima para el periodo legislativo de 1956 a 1962 y formó parte de la lista presidida por José Gálvez con candidatos al Senado y a Diputados por Lima. En esa época, el Senado estaba compuesto por 53 miembros, la Cámara de Diputados por 182 y el periodo del mandato era de seis años. Otra diferencia respecto a la actualidad, radica en que los candidatos y partidos debían elaborar sus propias cédulas de votación con pautas establecidas por el Jurado Nacional de Elecciones (JNE). La cédula del Congreso era distinta la de la plancha presidencial. Para inscribirse como candidatos, tenían que presentar la adhesión de 300 electores para el Senado y de 150 para Diputados, además de entregar a la Caja de Depósitos y Consignaciones 1,000 soles si se aspiraba a ser senador o 500 soles oro para diputado. (Rebata, 2015).

Entre las organizaciones políticas que alcanzaron al menos un escaño podemos señalar que compitieron tres partidos políticos: el Movimiento Democrático Pradista (MDP), la Unificación Nacional (UN) y el Partido Demócrata Cristiano (PDC), además de once listas independientes (LI) (Rebata, 2015, p. 109).

Las organizaciones y sus candidatos tuvieron muy poco tiempo para organizarse y participar en la contienda electoral. El PDC logró inscribirse ese año de 1956. Pero en el caso de Acción Popular (AP), en un principio el JNE no aceptó su 
registro y tuvieron que presentarse como el movimiento independiente Frente de Juventudes Democráticas (FJD) y lograron la inscripción como partido político después de esas elecciones.

La UN representaba a la oligarquía y en un principio, como sostienen Pease y Romero (2013), contó con el apoyo de Odría, quien había perdido legitimidad. El candidato a la presidencia de ese partido fue Hernando de Lavalle, conservador y dedicado a las finanzas. Sin embargo, sus orígenes estuvieron en la Coalición Nacional que organizó Beltrán en los últimos ańos de Odría para formar un frente amplio contra la perpetuación de este en el poder y que en su momento promovió la candidatura de Pedro Rosselló (Lossio y Candela, 2019, pp. 120-124). El segundo candidato fue el expresidente Manuel Prado y Ugarteche, para quien sus seguidores crearon el Movimiento Democrático Pradista (MDP); una vez en el gobierno modificaron dicho nombre y lo registraron como Movimiento Democrático Peruano. El tercer candidato fue Fernando Belaunde Terry, que a diferencia de los dos anteriores, representaba lo más moderno y progresista en el ámbito de una propuesta moderada. Su movimiento, el FJD, ofrecía renovar la política, incluida la esperada reforma agraria, aspecto que hizo temer al PAP la posibilidad de perder un espacio en el espectro político. Este era el elector principal, pero no estaban convencidos de Lavalle y temían perder espacio ante la irrupción de Belaunde en la escena política. Tomando eso en consideración y además la expectativa de poder inscribirse para competir en las elecciones de 1960, decidieron apoyar a Prado. Lo mismo hizo Odría, quien dejó de apoyar a Lavalle y se unió a Prado para garantizar que no se procesen los excesos cometidos durante su gobierno (Pease y Romero, 2013, pp.163-164).

La elección fue el 17 de junio de 1956 y la lista independiente (LI) de José Gálvez obtuvo 21 escańos, de los cuales 
seis fueron senadores y quince diputados. Así, se convirtió en la cuarta fuerza política, a pesar de haber presentado solo dos listas (de Lima para ambas cámaras). La primera fuerza política recayó en el MDP, que presentó listas en 17 circunscripciones para senadores y 19 circunscripciones para diputados; logró 24 senadores y 64 diputados. La segunda fuerza política fue UN y la tercera, el FJD.

Los senadores de la LI de José Gálvez fueron el propio José Gálvez Barrenechea, RPB, Ismael Bielich Flores, Antenor Fernández Soler, Alejandro Barco López y Víctor Salas Meléndez. Porras obtuvo un total de 121,941 votos y fue el segundo más votado de los 53 senadores, solo superado por los 127,530 votos de José Gálvez Barrenechea. Compartieron dicha representación con la primera mujer senadora del país, Irene Silva de Santolalla, de la lista de UN por Cajamarca con 18,094 votos (Poulsen, 2017, p. 143).

Si bien RPB estuvo en la mencionada lista independiente por Lima, ellos se solían denominar Frente Democrático Independiente o Frente Democrático Nacional. Su líder, José Gálvez, era famoso y tenía mucho reconocimiento especialmente en la ciudad de Lima. En sus años mozos había sido el "poeta de la juventud», luego fue vicepresidente de la República durante el gobierno de Bustamante y Rivero, además era tío de nuestro personaje. En junio de 1956, once días previos a la jornada electoral, lanzaron un manifiesto a los limeños diciendo, según palabras del propio Porras:

[...] queríamos volver a un renacimiento de la conciencia pública y de las fuerzas de opinión para que la voluntad del pueblo vuelva a mostrarse libre y soberana a pesar de las maniobras, de la corrupción, del engaño y del adelanto en la técnica de la falsificación, para dar paso, a un empeño democrático de verdad, que ponga término al abuso del poder y al desdén por el Derecho. Decíamos también que lucharíamos contra el personalismo presidencial omnipotente y la viciosa estructura del Estado, para crear 
un clima cívico de respeto a la ley, en que el Estado no sea opresor de la nación sino servidor de ella. (Senado de la República. Diario de Debates (DD). 1 ra. Leg. de 1956. 2do. vol. pp. 224-235).

El pronunciamiento de campaña de la lista independiente en la que participó RPB estaba orientado a marcar la transición política hacia un periodo de democratización del país. En esa democratización, los ciudadanos y -a partir de esas elecciones- las ciudadanas con derecho al sufragio debían involucrarse en los asuntos públicos con total libertad. Plantearon, en ese sentido, dejar atrás el ochenio, el autoritarismo y los procesos electorales no competitivos, como el de 1950. Una vez producidas las elecciones, cada uno de los representantes ocupó su lugar en un escaño, lo que dio inicio al conjunto de legislaturas, manera propia del trabajo parlamentario.

En ese contexto de transición política, Raúl Porras Barrenechea fue un protagonista, cuya actuación estuvo centrada primero en el Senado de la República y dos años después en la cartera de Relaciones Exteriores. Tal como he señalado al inicio, corresponde analizar su papel de representación política de manera sintética. Fue elegido por sus correligionarios como primer vicepresidente de la Cámara de Senadores en la legislatura de 1956. Luego, asumió interinamente la presidencia de senadores en 1957 a raíz de la muerte de su presidente. Integró las comisiones de demarcación territorial, educación, redacción y diplomática. Producto de ello, su labor parlamentaria se plasmó en 104 documentos parlamen-

210 tarios entre pedidos, proyectos (proyectos de ley, proyectos sustitutorios, dictámenes, mociones de orden del día), distribuidos en los tres ańos de acuerdo con el siguiente gráfico: 
Figura 2. Labor parlamentaria de Raúl Porras Barrenechea: pedidos, proyectos y mociones, 1956-1958

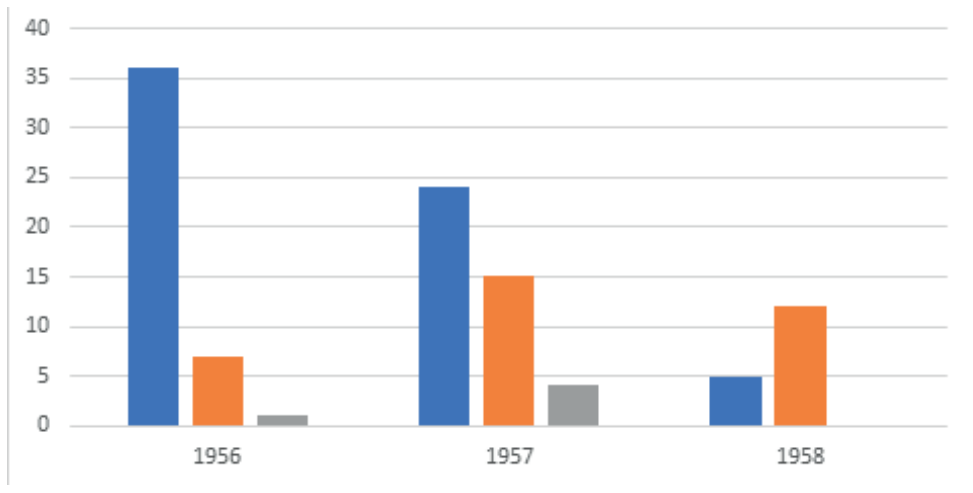

Fuente: Archivo del Congreso de la República. Elaboración propia. (Primera columna: pedidos; segunda columna: proyectos de ley, proyectos sustitutorios y dictámenes; tercera columna: mociones de orden del día)

Mención aparte merece su calidad de eximio orador en el hemiciclo del Senado. Fueron notables sus intervenciones en torno a la educación y el respeto a la tradición diplomática del Perú, así como sus eruditos homenajes a personajes y lugares del país, y el reconocimiento de los países amigos por su aporte a la cultura peruana. Sus intervenciones generalmente arrancaban aplausos de los otros senadores, diputados, trabajadores del Congreso y del público que se ubicaba en las galerías; así quedaron registradas dichas expresiones en el Diario de Debates (DD) del Senado en las legislaturas de 1956 y 1957. Es más, sus discursos eran tan impactantes que adolescentes de esa época, como Enrique Bernales, apreciaron la importancia del Senado gracias a Porras (El Comercio, 9-10-2017).

Entre 1958 y 1960 fue ministro de Estado en el despacho de Relaciones Exteriores. Por esas nuevas responsabilidades, su presencia en el Parlamento disminuyó significativamente. Sin embargo, en 1958 a pesar de su recargada agenda, se 
dio tiempo para ir al Congreso a firmar algunos dictámenes y presentar pedidos. En el siguiente acápite, desarrollo en detalle su iniciativa legislativa, su labor de fiscalización, el rol de representante y su aporte en la deliberación de temas complejos en los cuales participó con toda su capacidad y erudición. De ello, el lector podrá apreciar que RPB contribuyó de manera significativa a lo que Delgado Guembes (2011) señala como cultura parlamentaria. Es decir, aquel conjunto de contenidos deseables en la actividad política de los representantes del Congreso (p. 93).

\section{Proyectos de ley}

A continuación, analizo la actividad parlamentaria de RPB de acuerdo con su función de legislación, fiscalización, representación y deliberación (Pease, 2006, p. 23). Para ello, doy cuenta de su labor legislativa, que incluye mociones de orden del día, pedidos, proyectos de ley, proyectos sustitutorios, dictámenes y sus principales intervenciones, pues son las principales fuentes primarias disponibles. Para el estudio y análisis de la función denominada iniciativa legislativa, de ese conjunto de fuentes primarias mencionadas, analizo los proyectos de ley, cuya autoría puede ser individual o colectiva (como bancada o multipartidaria) (Bernales, 1990, p. 219), los proyectos sustitutorios elaborados en las comisiones del congreso y los dictámenes (mayoría o minoría) que se emiten en las comisiones. La función de control político se puede expresar en las mociones de orden del día o en los pedidos (orales o escritos) (Bernales, 1990, p. 56). De igual manera, la función de representación se puede ejercer en los proyectos, mociones de orden del día, intervenciones en el hemiciclo o en los pedidos. Finalmente, la función de deliberación se expresa cuando en el debate con otros senadores se van modificando o afirmando las posturas, así como en la elaboración de los dictámenes resultado del trabajo en las comisiones. 


\subsection{Iniciativas legislativas}

Para iniciar este subacápite, debemos recordar que la labor de presentar proyectos de ley no es única ni la más importante para un parlamentario. Como sostiene Eguiguren, la función legislativa también la ejerce el Ejecutivo. En esa línea, más importante que legislar es representar (Chávez y Medrano, 2008). En ese mismo sentido, Pease afirma que la función de representación y gestión de intereses y demandas de los pueblos es de lejos la función que más legitimidad da ante la ciudadanía (Pease, 2006, p. 24). De la misma opinión es Bernales respecto a la función primordial de la representación (1990, cap. 6). El Parlamento, cuando es bicameral, una representa a una parte (los intereses locales) y la otra, especialmente el Senado, debería representar al todo (los intereses nacionales o regionales) de los electores. Históricamente, se trata de una institución que se fue especializando desde el mundo moderno cuando la perspectiva del todo, encarnada en ese entonces por el príncipe, pasó a ser considerada por la comunidad política (Fioravanti, 2011). Desde ese punto de vista, el legislador es un representante popular y en su nombre ejerce una representación para formular leyes, deliberar, ejercer el control político y canalizar las demandas, intereses y expectativas de la sociedad a través de la representación (Chávez y Medrano, 2008, p. 15).

Desde esa perspectiva, Porras Barrenechea participó en la formulación de treinta y cuatro proyectos (de ley, de resolución legislativa, sustitutorios y dictámenes). Dichos proyectos fueron presentados de la siguiente manera: siete en 1956, quince al año siguiente y doce en 1958. Entre los temas abordados en dichos proyectos destacan la creación de distritos, promoción del desarrollo local, sobre la transición política y los de educación y cultura. Del total de proyectos, solo dos fueron presentados de manera individual. El primero, del 18 de diciembre de 1956, propuso crear el Instituto Nacional 
Industrial de Varones en Chancay. El segundo, del 12 de setiembre de 1957, consistió en declarar vacante una senaduría por Lima debido al fallecimiento de José Gálvez. En ambas iniciativas legislativas, se puede apreciar que la función de representación fue ejercida por RPB en tanto fue elegido por Lima y para atender una demanda de su bancada, respectivamente.

Entre los proyectos multipartidarios suscritos por RPB, podemos mencionar en primer lugar el que presentaron once senadores pertenecientes a cinco bancadas (cinco del MDP, dos de la LI de Luis González, dos de la LI de José Gálvez, uno de UN y uno de la LI de Wilson Sologuren). Este proyecto, en el contexto de la transición política, fue denominado «Ley de Amnistía" y concedía amnistía general a todos los procesados o sentenciados por temas políticos, sean civiles o militares, y derogaba la Ley de Seguridad Interior vigente durante el ochenio. Si se recuerda el contexto de transición política, podremos comprender que un papel central del Parlamento fue facilitar políticamente dicho cambio, especialmente en el trato a la oposición y en el camino hacia la democratización (Thibaut, 2006; Tilly, 2007). Nótese, además, que a pesar del apoyo de Odría a la candidatura de Prado para evitar asumir la responsabilidad política del ochenio, era inevitable que en el Parlamento se presenten proyectos que tendieran hacia la liberalización como parte de esa transición política. Por eso, no es casual que cinco senadores del MDP, a pesar de ser oficialistas, suscribieran dicho proyecto de amnistía.

Sobre proyectos orientados al desarrollo local, nuestro personaje se adhirió a la iniciativa del senador por Ica, Alberto Martinto, quien pertenecía a la bancada del MDP. Dicho proyecto consistía en la construcción de casas-granjas y casashabitación en Ica. Si bien Porras era senador por Lima, su lugar de nacimiento fue Pisco, en Ica, de ahí que consideró importante suscribir dicho proyecto. Se trataba de una ini- 
ciativa que contribuiría a mejorar las condiciones materiales de sus "paisanos». Así, la función de representación del RPB no se limitó a sus electores de Lima, sino que se extendió al lugar de su nacimiento. Es preciso indicar que en esa época la representación estaba dada por la circunscripción electoral por la que compitieron en las elecciones. Sin embargo, por la propia naturaleza del Senado que he mencionado en párrafos precedentes, los senadores solían legislar pensando en el ámbito nacional y no solo local, ni restringido a la circunscripción por la que fueron elegidos.

Otro proyecto, cuya iniciativa abarcó más de una bancada, fue el presentado en diciembre de 1957 para la creación del timbre «Fondo Poder Judicial» con valor de cien soles oro. Este proyecto fue multipartidario: UN, cuyo senador Alberto Arca Parró tuvo la iniciativa; el FJD (AP), MDP, las LI de Luis González y de José Gálvez. Era un proyecto destinado a incrementar el presupuesto del poder judicial. Por ello, contó con el apoyo de diez senadores, entre abogados, juristas y los comprometidos con mejorar las condiciones materiales de la administración de justicia. Por lo tanto, la representación ejercida en este caso por RPB fue social y gremial.

En síntesis, en este acápite apreciamos que Porras ejerció la función de iniciativa legislativa con catorce proyectos y los llevó a cabo como representante de Lima, de su bancada, de sus gremios, de sus electores de Lima, de su lugar de nacimiento y de la comunidad de peruanos en general.

\subsection{Dictámenes y proyectos sustitutorios}

Fueron un total de veinte los dictámenes suscritos por Porras como integrante de las dos comisiones en las que participó, la Comisión de Educación A y la Comisión de Demarcación. En la primera comisión firmó con el senador por Lima Rodrigo Franco, del MDP, y con la senadora por Cajamarca Ire- 
ne Silva de Santolalla, de UN. Respecto a la segunda comisión, firmó los dictámenes con el senador por Huancavelica Celestino Manchego y con el senador por Loreto Guillermo Orbegoso, ambos del MDP. Si analizamos la composición de ambas comisiones, constatamos que la Comisión de Educación A tenía una conformación más plural, pues había un integrante del partido del gobierno y dos de la oposición, mientras que la comisión de Demarcación no lo era tanto, ya que dos de tres integrantes eran del partido del gobierno y uno de la oposición. En ningún caso hubo dictamen en mayoría y en minoría, por lo que ambas comisiones trabajaron en consenso los proyectos sustitutorios que presentaron al pleno.

$\mathrm{Si}$ analizamos los treinta y cuatro proyectos, solo dos fueron presentados de manera individual y los otros contaron con la adhesión de siete de las diez bancadas que conformaban el Senado de entonces. Así, logró que se adhirieran seis senadores del MDP, cinco de su propia bancada, tres del FJD, igual número de UN, y obtuvo una adhesión del PDC, de la LI de Rodrigo Alonso y de la LI de Augusto Guzmán. Podemos afirmar que nunca hubo adhesión de tres bancadas que participaron como LI de Edgardo Portaro, senador por Pasco, de Wilson Sologuren, senador por Tacna, ni de Luis González, senador por La Libertad. Asimismo, Porras adhirió iniciativas de integrantes de cinco de las diez bancadas. De ellas destacan por el número, su adhesión a once iniciativas del MDP, y luego de las bancadas de UN (3), PDC (2), de su propia bancada 2 y 1 de Wilson Sologuren. Sus adhesiones a las iniciativas de los senadores van de 1 a 4 . Así, adhirió a 4 iniciativas de Mario Polar Ugarteche del PDC y senador por Arequipa, y el mismo número de adhesiones a las iniciativas del senador Alejandro Barco López, representante de Lima y miembro de su bancada. Luego, adhirió a 3 iniciativas de Celestino Manchego, senador por Huancavelica e integrante del MDP. Todo ello demuestra su espíritu plural y predispo- 
sición a entrar en diálogo. Con este ejemplo, podemos observar la ardua tarea que implica conseguir proyectos multipartidarios, pues así es como se van aglutinando y canalizando los intereses de los representados.

\subsection{Mociones de orden del día}

Raúl Porras Barrenechea presentó un total de cinco mociones de orden del día. La primera moción fue en 1956 y las otras cuatro al año siguiente, todas multipartidarias. En una sola tuvo la iniciativa y logró la adhesión de 2 senadores, uno de ellos fue de su bancada, Alejandro Barco López, y el otro del MDP, Miguel Monteza Tafur. La moción establecía una comisión para examinar las infracciones constitucionales cometidas por el expresidente Manuel A. Odría; con ello, ejerció su función de fiscalización. La moción fue intensamente discutida y las bancadas no tenían una postura al respecto. Por ejemplo, el MDP tenía congresistas que estaban a favor y otros en contra. Esto es particularmente relevante si recordamos la famosa «convivencia» Prado-Odría-Haya. Sorprende el caso del FJD, pues a pesar de ser la segunda fuerza política, algunos no apoyaron la moción al considerar que no había que mirar el pasado, sino más bien concentrarse en el futuro (DD Leg. 1956, 14 ago.1956). El caso es que esa moción finalmente fue aprobada, pero el MDP se adelantó a la conformación de la comisión y no incluyó a los autores de dicha moción. De los cinco miembros que la conformaron, tres de ellos eran oficialistas del MDP, Víctor Arévalo, Eduardo Battifora y Manuel Cacho, el cuarto integrante fue Luis González, quien presidió una lista al Senado por La Libertad y el último fue Mario Polar Ugarteche del PDC (DD Leg. 1956, 16 ago. 1956). Lo que podemos observar en este caso, es que si bien no se pudo evitar que Porras y otros presentaran la moción, la mayoría tomó medidas para controlar la conformación de dicha comisión, probablemente para evitar romper la «convivencia» pactada durante la campaña 
electoral. La reacción de la LI de José Gálvez fue renunciar a la presidencia del Senado, ejerciendo así su fuerza política. Por ello, se renegoció la recomposición de la misma y se ratificó a Gálvez en la presidencia del Senado.

Sobre las otras mociones, Porras adhirió 2 mociones presentadas por Mario Polar Ugarteche, del PDC. Ambas incidían en la función de control político. La primera para interpelar al ministro de Relaciones Exteriores, Hacienda y Comercio, y al de Fomento y Obras Públicas. Deseaban que los interpelados respondieran principalmente sobre las medidas para hacer frente a la caída de los precios internacionales del zinc y el plomo, y para la definitiva ejecución del Tratado de Río de Janeiro (29-1-1942), entre otros temas. Es pertinente mencionar que el Perú había reprimarizado su economía y dependía de la exportación de materias primas, por lo que se encontraba al vaivén de las fluctuaciones de los precios internacionales.

La cuarta moción suscrita por RPB de iniciativa del senador Pedro Alva de la bancada Unidad Nacional consistió en dar un voto de aplauso a la Sociedad de Beneficencia Pública de Lima. Una última moción fue de otro miembro de su bancada, Alejandro Barco, quien rindió homenaje al ejército peruano por el aniversario de la batalla de Ayacucho. Así, ejerciendo la representación del pueblo peruano, senadores de diversas bancadas - UN, FJD, MDP, LI de José Gálvez, LI de Luis González, LI de Augusto Guzmán, el PDC y la LI de Rodrigo Alonso - recordaron la fecha de consolidación militar de la independencia al ganar la batalla de Ayacucho al ejército realista.

En resumen, Porras, junto con senadores de otras bancadas presentaron mociones de orden del día ejerciendo principalmente su función de control político, así como la de representación. 


\section{Pedidos}

La obra parlamentaria de Raúl Porras Barrenechea estuvo centrada mayormente en ejercer la función de representación política, frente a las otras funciones de iniciativa legislativa, de deliberar o la de control político. Esto ha sido constatado con los proyectos y mociones analizados. Sin embargo, en los pedidos presentados, tanto individual como colectivamente, es donde nuestro personaje ejerció a plenitud esta función. $\mathrm{RPB}$ presentó un total de 65 pedidos, cifra que se distancia significativamente de los 34 proyectos y 5 mociones suscritas por él. Porras era muy consciente de su rol de representación, por eso en una sesión del ańo 1957 sostuvo: “... deseo simplemente hacer unos cuantos pedidos, que provienen principalmente del oficio de intermediarios que realizamos los representantes" (DD, sesión del 30 de diciembre de 1957).

En 1956 presentó treinta y seis pedidos, al año siguiente veinticuatro y en 1958 cinco. Básicamente, los pedidos giraron en torno a seis temas principales de acuerdo con el siguiente detalle:

- Transición política y democratización

- Promoción del desarrollo local

- Reconocimiento a personajes u organizaciones.

- Relaciones exteriores

- Cultura y educación

- Socio-laboral

- Otros.

Otra manera de comprobar el peso de la función de representación a través de los pedidos es cuando los sustentaba. Casi siempre, mencionaba que había recibido a una delegación de abogados, trabajadores, estudiantes, funcionarios, empleados, agricultores, entre otros. Cuando recorría el país también recibía peticiones de diversos miembros de la sociedad. Resultado de ese contacto, canalizaba dichas demandas hacia 
el ámbito público, les hacía seguimiento y se preocupaba por su atención. Debido a lo limitado del espacio, solo presentaré los pedidos sobre la transición política y democratización, así como los de relaciones exteriores.

Los pedidos presentados por Porras durante el contexto de transición democrática fueron tres. A diferencia de las mociones que fueron multipartidarias, estos fueron individuales y no tuvieron adhesiones. En el primer pedido, complementario al proyecto de ley de amnistía política, solicitó que el Senado oficie al ministro de Justicia para que los Registros Públicos y los bancos procedieran a levantar las anotaciones de embargo a los bienes de los enjuiciados por delitos políticos. Este pedido se hizo en cumplimiento de su función de representación, orientado a restablecer el Estado de derecho (DD Leg. 1956, sesión 16 ago. 1956, pp. 155-162). En el segundo, ejerciendo la función de control político, pidió que se devuelva al ministro de Justicia y Culto los expedientes de los postulantes a vocales de la Corte Suprema, por no estar de acuerdo con los requisitos establecidos por la ley. En ese sentido, identificó que los candidatos propuestos no cumplían con el perfil, lo que en un contexto desdemocratizador, como el ochenio, era bastante común. El tercero fue un saludo al PDC al cumplir 2 años de fundación. Recordemos que en toda transición democrática se produce una liberalización política, que permite que surjan nuevos partidos políticos o se facilite su inscripción. Por lo tanto, en ese pedido ejerció la función de representación de una bancada que se formó en la etapa de liberación política durante la transición política.

Nuestro senador suscribió siete pedidos sobre relaciones exteriores, de los cuales solo uno tuvo la iniciativa de otro senador, el resto fueron de su autoría. De esos seis, logró la adhesión en dos -el saludo al Brasil por el 134 aniversario de su independencia y que el ministro de RR. EE. y el de edu- 
cación informen con qué autorización se obsequió un manto Paracas a la ONU - este último, claramente en cumplimiento de la función de fiscalización.

Un pedido orientado a la consolidación de la presencia peruana en el concierto internacional fue aquel que solicitaba la designación de peruanos con el rango de ministro en los órganos especializados de las Naciones Unidas. Esto tenía consonancia con el contexto internacional, pues la ONU surgió luego de la Segunda Guerra Mundial para mantener la paz y la seguridad internacional, y también para fomentar relaciones de amistad y cooperación entre las naciones.

En otro pedido, saludó que el ministro Cisneros de ese entonces retomara la sana política de respetar la carrera diplomática y solicitó que se aplique la ley del servicio diplomático, aspecto que se había perdido durante el ochenio.

Otro pedido fue para que se agradezca al conde de la Cortina la adquisición de la casa del Inca Garcilaso de la Vega por su donación al pueblo de Montilla (España) para instalar un museo y la embajada debía contribuir en ello. En ese caso, podemos apreciar que Porras compatibilizó su experiencia en el Ministerio de Relaciones Exteriores, sus estudios históricos sobre Garcilaso de la Vega y su labor parlamentaria para valorar y promover que la casa-museo del Inca Garcilaso de la Vega pueda hacerse realidad en la ciudad de Montilla, lugar donde residió el "primer mestizo» peruano.

\section{Principales intervenciones en el hemiciclo y la función deliberativa}

La deliberación es una función central en los parlamentos. Se trata de intercambiar posturas y argumentos hasta lograr que en ese ejercicio se tomen en consideración los criterios vertidos durante el debate de un tema. Implica el manejo del arte de la persuasión y el ponerse de acuerdo. Es tan importante 
para la toma de decisiones que Schmitt describió al parlamento como el lugar donde se realiza la discusión pública de las opiniones políticas (Schmitt, citado en Santaolalla, 2013, p. 49). Para Santaolalla, el parlamento es una institución deliberante por excelencia, pues responde al hecho de ser un órgano representativo, por lo tanto, en democracia este es plural, heterogéneo y diverso, al igual que la sociedad a la que representa. Para funcionar de acuerdo con ello, entonces, las decisiones deben ser colegiadas (pp. 49-52).

$\mathrm{RPB}$ destacó por sus intervenciones en el hemiciclo, pues fue un orador con dominio del lenguaje y capacidad argumentativa. Los temas en los cuales intervino expresan sus valores, posición política y sensibilidad social y cultural. Intervino en asuntos de la democracia en el Perú, la educación y cultura, las relaciones exteriores, el desarrollo local, el respeto a los derechos de los diversos grupos sociales, así como en la rememoración y homenaje que se debía ofrecer a personajes y organismos destacados. Sus intervenciones tenían el objetivo de mostrar su punto de vista para que sea tomado en consideración. Por ejemplo, en un debate señaló lo siguiente: «Debe, pues, a mi modo de ver, reformarse la escala (...) tomando en cuenta las anotaciones que se han hecho en el debate, porque para eso son los debates parlamentarios, para tomar en cuenta las opiniones de todos (...)» (DD 1 ra. leg. 3er. vol., p. 388). Al igual que en el acápite anterior, por limitaciones de espacio solo daré cuenta de algunas intervenciones relacionadas con la transición democrática y las relaciones exteriores.

Dada la transición política del ochenio al segundo gobierno de Prado, uno de los primeros temas abordados en el hemiciclo fue la conformación de una comisión investigadora para que estudie si el gobierno de Odría violó o no la Constitución. Un fragmento de sus intervenciones muestra su postura sobre una transición adecuada hacia la democracia: 
[...] creo yo, que el defecto capital de nuestra democracia [...], es el de la falta de adaptación entre las leyes importadas [...] y nuestra compleja realidad étnica y social, entre la democracia ideal y la irrisoria democracia vivida. Constituidos los gobiernos al margen de la opinión pública, surgen estos sin que exista la comunidad entre la autoridad y el pueblo que brota de todo proceso electoral libre y de ello viene la simulación de las instituciones, la palabrería demagógica junto a la conculcación de las libertades, las triquiñuelas y las mentiras (el llamar bueno a lo malo y malo a lo bueno, negro a lo blanco y blanco a lo negro), el ambiente de hipocresía y de desconfianza ante las fórmulas mismas de represión simuladas y evasivas de la responsabilidad. En los tiempos que nos preceden se ha simulado el sufragio apresando al candidato contrario, se ha simulado la igualdad quitando la ciudadanía a un gran número de peruanos, se ha simulado el respeto a la Constitución encerrándola bajo siete llaves, se han simulado las libertades de reunión y de opinión proscribiendo a los partidos contrarios, se han simulado las libertades municipales entregando los municipios a [...] las oligarquías provinciales o poniendo el derecho de reunión a la discreción de los tanques o de los manguerazos. Todas las $[\ldots]$ instituciones resultan falseadas en nuestro medio por el predominio del provecho personal y la ausencia del propósito del bien común. (DD. 1 ra. leg. de 1956, 1er. vol. pp. 101-106).

Recordemos que entre 1930 y 1968 nuestro país vivió el periodo denominado "crisis del orden oligárquico», por ello, muchos hombres y mujeres de bien y capaces fueron dejados de lado para beneficiar a los aduladores al poder, especialmente al poder autoritario. Ese periodo envuelto en la incertidumbre y arbitrariedad fue muy nocivo para el país, tal como señalaba Porras, «el mal proviene de nosotros mismos porque no tenemos un ideal colectivo" (Senado de la República del Perú. DD. 1ra. leg. de 1956, 1er. vol. pp. 101-106).

Porras explica que el problema de ese tipo de «democracia», es decir, de un gobierno autoritario que se irroga un discurso democrático, como en el ochenio, se debe a la falta de ciudadanía. Basta revisar los periódicos del ochenio para constatar 
las fuertes campañas de despolitización que promovió dicho régimen. Incluso, cuando se refiere a la ausencia de «ideal colectivo», prácticamente se refiere al fracaso de la nación peruana como comunidad política. Nótese la claridad de Porras al señalar cuáles son las consecuencias de un gobierno autoritario que se irroga ser democrático. El resultado no es otro que la improvisación en la vida pública. Mal que se padeció durante nuestra vida republicana.

Como en todo periodo de transición del autoritarismo militar a un gobierno oligárquico semicompetitivo, también era necesaria la amnistía a los presos políticos, de ahí que se presentara un proyecto de ley de amnistía a presos políticos y la derogación de la Ley de Seguridad Interior, asuntos de los que ya di cuenta. En el debate del proyecto, nuevamente la voz de Porras apeló a la necesidad de vivir en un país donde la libertad de opinión se respete plenamente y las opiniones disonantes no tengan que ser condenadas (DD 1 ra. leg. de 1956, 1er. vol. pp. 101-106).

El argumento más contundente señalado por RPB fue haber vivido en estado de sitio permanente a lo largo del ochenio. De ahí que fuera imperioso que el nuevo gobierno restableciera el Estado de derecho y volvieran a estar vigentes las leyes y el respeto a los derechos. Podemos apreciar al Porras republicano preocupado, porque la discordia, división y conflicto interno son problemas que ponen en riesgo la continuidad de las comunidades políticas. El Perú, durante el siglo XX al

224 ser víctima del enfrentamiento entre ciudadanos, tal como era percibido por RPB, había generado muchos males al país.

Meses después, en octubre de 1956, RPB intervino para rendir homenaje por los cien años de la promulgación de la Constitución de 1856 y a su vez recordar a los constituyentes de ese entonces. Dicha Constitución, según sus palabras, fue considerada la más liberal del país al seguir las ideas de los constituyentes de 1822 y 1827 . Su objetivo central era refre- 
nar la excesiva influencia de los presidentes de la república y el predominio de la casta militar en los destinos del país. Entre sus principales autores destacó a José Gálvez, Dean Valdivia, Ignacio Escudero, Manuel Toribio Ureta, entre otros (DD Leg. de 1956, 3er. vol. pp. 111-114). Aquí estamos ante un RPB liberal. Si comparamos este y el párrafo anterior, podríamos considerarlo en el contiuum republicanismoliberalismo democrático propuesto por Máiz, al no optar por la simple agregación de demandas de la sociedad hacia la esfera pública, sino optar por una nueva síntesis de comunidad política que atendiera problemas estructurales y a su vez recogiera tradiciones que fueron construyendo una trayectoria basada en principios (Máiz, 2006, p. 13).

A finales de 1957, el gobierno suspendió las garantías constitucionales y declaró en emergencia el país. Se trataba de una medida represiva ante el incremento de los conflictos sociales y laborales en el ámbito nacional. El Senado no estuvo ajeno a la preocupación de volver a periodos autoritarios, por eso Porras se opuso, ya que le preocupaba que el Estado de derecho se quebrara o se impidiera la libre discusión de ideas, lo que podría generar deslizamientos hacia la desdemocratización. De ahí que, entre sus argumentos, sostuvo que:

[...] La democracia es precisamente discusión y no se puede subsistir cuando se están suspendiendo una serie de garantías, de libertades que están ordenadas por la Constitución, cuando se está suspendiendo la libertad de reunión, [...] la libertad o el derecho de inviolabilidad de domicilio, de las cartas y otras garantías, cuando sabemos, extraoficialmente, que se ha allanado un periódico y que se ha tomado presos a una serie de peruanos [...] en realidad lo que está en peligro es la democracia, porque democracia es en esencia discusión, es [...] colaboración crítica; democracia es perseguir el bien común y el bienestar general y no perseguir a otros peruanos. (DD Leg. 1957, 3er. vol. pp. 464-465). 
Sobre la política internacional peruana y la carrera diplomática, RPB hizo notables aportes. Hay un conjunto de principios en este sector que nuestro personaje defendió en todos los foros donde estuvo. Una breve síntesis de ello se pudo apreciar en la siguiente intervención:

[...] Breve y simplemente quiero decir, que, si hay una cosa estable [...], es nuestra orientación internacional. [Esta] fue siempre en defensa de las situaciones de derecho sobre las situaciones de fuerza y en defensa de la coordinación de los esfuerzos internacionales desde la Circular del Congreso de Panamá enviada por Sánchez Carrión hasta los Congresos del 48, convocados por Castilla, en pleno peligro del imperialismo español y luego [...] protestando contra todos los atentados de fuerza de América, contra la ocupación de México, favoreciendo la libertad de Cuba y apoyando al Paraguay contra las fuerzas tripartitas de Argentina, Brasil y Uruguay... [En síntesis] si algo en la República, ha tenido uniformidad y continuidad, es la línea diplomática internacional en favor de la paz y el derecho. (DD 1 ra. leg. 1956. 2do. vol. p. 99).

Nótese que esos principios se sumaron a su postura de no intervención en los asuntos internos de los países y fueron puntos que siempre mantuvo. Por ello, es necesario considerar que cuando en 1958 Prado lo invitó a ser ministro de Relaciones Exteriores, sabía bien cuál era la postura de Porras.

El Senado recibió la visita de Carlos de Macedo Soares, ministro de Relaciones Exteriores del Brasil y, entre otros ora226 dores, RPB tomó la palabra para destacar la importancia de la Amazonia, ya sea en el pasado, presente y futuro de ambos países. Luego, para explicar las relaciones diplomáticas a lo largo de la historia entre el Perú y el Brasil expresó el valor histórico del Tratado de 1851 suscrito por ambos gobiernos, que para nosotros era la primera frontera definitiva que se logró con los países vecinos, incluida la libre navegación por el Amazonas. El principio de posesión fue la base de tan es- 
tratégico tratado (DD 1ra. leg. extraord. de 1957, 1er. vol. pp. 59-66).

Respecto a los Estados Unidos, su intervención giró en hacer respetar nuestra soberanía y cultura. De ahí que advirtió sobre el Instituto Lingüístico de Verano y precisó que el nombre de dicho instituto daría la impresión de ser transitorio o estacional, que funciona durante el verano, pero que no era así. Llegaron en 1945 y pensaban quedarse quince años adicionales. El objetivo inicial era estudiar las lenguas amazónicas, pero luego establecieron puestos de sanidad y campañas para castellanizar la selva, aspecto contradictorio, pues ellos hablan inglés. Pero lo más crítico era la intención de ubicarse en zonas fronterizas:

Las zonas del Purús y de los Mascos son fronterizas. No es conveniente para el Perú que en zonas fronterizas se establezcan institutos extranjeros que no dependen de ministerios del Perú, sino de autoridades extranjeras y que ejercen funciones, dirigen la sanidad, la instrucción y todas las actividades. Creo que ningún país acepta esto y tampoco nuestra Constitución lo permite. (DD 1957, pp. 620-624).

Respecto a Gran Bretańa, a RPB le correspondió pronunciar el discurso de orden ante la visita del vicecanciller parlamentario de relaciones exteriores de Gran Bretaña. Inició destacando la experiencia e importancia del invitado. Luego, expuso que las relaciones con Inglaterra se remontan a los primeros años de la presencia española en tierras americanas. Mencionó a Walter Raleig, a quien denominó el «primero de los heraldos europeos de la opulencia peruana». Después dio cuenta de la presencia de los corsarios en las costas peruanas, quienes pueden ser vistos como mensajeros de la libertad pues «al recorrer y saquear las costas del Perú y al llevarse los tributos que impusieron la esclavitud y el despotismo, combatían contra el absolutismo político». Durante la Emancipación, Inglaterra fue el lugar donde conspiraron los 
emigrados peruanos, quienes fueron acogidos por los ministros William Pitt y Canning. Otro de los aportes fueron sus militares enrolados en los ejércitos libertadores:

[...] Pero no solo la acción diplomática sirvió a la independencia del Perú, sino también, su contribución heroica y de sangre [...] [Vinieron] tres mil irlandeses, que formaron la célebre legión británica, se batieron y se hicieron diezmar [...] en la batalla de Carabobo. Los sobrevivientes formaron más tarde el batallón Albión, en la batalla de Pichincha [...] fueron legiones de oficiales y soldados ingleses que habían estado en la batalla de Bailén, en Waterloo, como Miller, o en Trafalgar, como Guise, [...] los que vinieron $[. .$.$] a pelear en los riscos de los Andes para obtener la$ libertad del Perú.

Los más grandes colaboradores extranjeros en nuestra independencia fueron los ingleses, en primer término Cochrane, [que] capturó en una noche de gloria la Esmeralda, y luego, Miller, [...] que se aclimata en el Perú, arraiga en él y se convierte en un verdadero criollo, viste el poncho peruano, monta el caballo de paso y luce el sombrero de jipijapa, que habla siempre con emoción y cariño de las cosas y de los usos del Perú, y después Guise, que forma nuestra primera escuadra y muere como Almirante en ella, defendiendo la integridad del Perú en Guayaquil [grandes aplausos en las galerías]. (DD Leg. de 1957, pp. 483-489).

Mencionó, además, la presencia de los viajeros ingleses que dejaron en sus libros sus apreciaciones de nuestra cultura. Destacó la importancia de la revolución industrial liderada por ellos, razón por la cual sostuvo que el país necesitaba la colaboración británica para poder diversificar nuestra economía e industrializarnos.

Cuando el presidente del Consejo de la República de Francia visitó el Congreso peruano en setiembre de 1957, hubo una sesión especial para darle la bienvenida. RPB intervino y señaló que lo hacía como maestro de historia y discípulo de Francia. Así fue como explicó la larga y enriquecedora rela- 
ción entre Francia y el Perú, las fuertes influencias recibidas, los peruanos que vivieron ahí y los franceses que nos visitaron. Fue una clase de historia de las relaciones entre ambos países, así como del legado de Descartes, Montesquieu, Voltaire hasta llegar a la Declaración de los Derechos del Hombre (DD, Leg. de 1957, 2do. vol. pp. 95-100).

El Senado volvió a escuchar a RPB cuando el gobierno propuso al presidente Eisenhower y al secretario de la OTAN promover un acercamiento con la OEA. Entre los argumentos de Porras estuvieron el hecho de que un país integrante de la OEA no puede hacer dicho planteamiento, pues no representa a los demás países miembros. Además, sostuvo que era inadecuado e improcedente, ya que las coordinaciones globales se canalizaban a través de la ONU y no procedía el acercamiento mencionado porque son específicamente regionales. Advirtió, por lo tanto, que había demasiado interés de la cancillería peruana de involucrarse en la guerra fría a favor de una parte, sin conocer de qué manera proceder.

[...] se ha dicho [...] que no se puede tomar en absoluto en cuenta esta actitud, porque los propios países que están interesados en esta lucha, [...] no desean dividir al mundo en dos bloques exclusivos. El Perú está demostrando su deseo anticipado, su deseo fervoroso, su deseo prematuro de incorporarse a esa lucha y ponerse en uno de los dos bandos [...] Muchas veces en la historia los pueblos han estado en una encrucijada semejante y la labor de los hombres que representaban el pensamiento cardinal de la humanidad, la labor de los humanistas, como en la época de la Reforma, ha sido, precisamente, evitar esa división en dos bandos. (DD 1957 2do. vol. pp. 88-90).

En el contexto de la guerra fría, Porras se opuso a cualquier iniciativa que hiciera que el Perú se inclinara por uno de los dos bandos, o que rechazara acuerdos comerciales con los países «detrás de la cortina de hierro». La posición de Porras fue que se podía seguir manteniendo relaciones comerciales con 
países totalitarios pues «ni el zinc, ni la harina de pescado, ni el algodón tienen opiniones políticas». Más bien, reclamaba a la bancada oficialista que no haya tenido esa misma actitud cuando la cancillería había enviado condolencias a algunos países latinoamericanos ante la muerte de tiranos, como Somoza y Castillo Armas (DD, 1 ra. leg. de 1957, 1er. vol., p. 6).

Las intervenciones de Porras sobre las relaciones internacionales peruanas giraron sobre los principios que como república se desarrollaron a lo largo del tiempo. Destacó la defensa de las situaciones de derecho sobre las situaciones de fuerza, la no injerencia en los asuntos internos de cada país, tener un concepto de soberanía equilibrado, defender nuestra cultura y no permitir que extranjeros se ubiquen en zonas fronterizas tratando de cambiar nuestra cultura y actuar al margen de las políticas de Estado. Asimismo, evitó polarizar al mundo en el contexto de la guerra fría.

\section{Conclusiones}

El contexto de transición política incidió directamente en la labor del Parlamento durante el periodo 1956-1962. Dicha transición y democratización, que dio lugar a la presidencia de Prado, significó recuperar la libertad de expresión, la inclusión de nuevos partidos políticos al sistema, la incorporación de nuevos electores y la reconstitución del tejido y la movilización sociales. En esa democratización era necesario fortalecer la ciudadanía, pues durante el ochenio se había despolitizado y desarrollado relaciones patrón-cliente con el poder.

Porras, que durante mucho tiempo de su vida se había dedicar a pensar en el país, se comprometió en el último lustro de su vida -especialmente mientras fue Senador por Lima- a la representación política. Para ello, canalizó las demandas de importantes sectores de la población en el interior del Par- 
lamento. Sin embargo, vale precisar que su incursión en los asuntos públicos no surgió al final de su vida, sino que se fue formando a lo largo del tiempo. Desde las aulas universitarias, hasta su vida profesional, participó en los asuntos públicos pensando en el Perú y representándolo cuando tuvo la oportunidad.

Como senador, suscribió 65 pedidos, 34 proyectos y 5 mociones. Cumplió a cabalidad sus funciones como parlamentario, pues fue un representante de la nación, legislador acucioso, responsable y activo en el control político. Y fue mucho más que eso. A lo largo de este artículo, he demostrado que con su labor parlamentaria contribuyó a la reconstitución de la función de representación política. Canalizó las demandas de la sociedad organizada -sindicato de trabajadores portuarios, yanaconas de Lurín, estudiantes y docentes de San Marcos, beneficiarios del Hospital del Empleado, afectados del Hospital del Niño, pobladores de provincias de Lima, entre otros- y las planteó en el hemiciclo del Congreso para que el Ejecutivo intervenga. Esto fue lo trascendente de su labor, pues el ochenio había distorsionado y quebrado la representación política, al personalizar la política en Odría y hacerla clientelista.

Actuó de acuerdo con sus principios y valores, y con ello afrontó el contexto histórico que le tocó vivir. Tal como señala Altamirano cuando analiza a los intelectuales del siglo XX, podemos señalar que RPB fue un actor preponderante en el debate público, fue la conciencia de su tiempo, intérprete de la nación, un moralista público. En fin, estuvo entre los intelectuales de la región latinoamericana que conformaron el reducido grupo ético que tanto se necesitaba en ese entonces y que se necesita hoy en día.

Recibido: 11 de octubre del 2020

Aprobado: 20 de abril del 2021 


\section{Fuentes y referencias bibliográficas}

\section{Fuentes}

Archivo digital del Congreso de la República. www.congreso.gob. pe/periodificaciondelcongreso

Diario La Prensa, varios números del año 1956

Diario de Debates, varios volúmenes, 1956-1958

Diario El Comercio, 1956-1958, 2017.

\section{Referencias bibliográficas}

Abanto, J.

(2017) El Congreso de la República durante la ocupación chilena: Chorrillos, Ayacucho, Cajamarca y Arequipa 1881-1883. Lima: Eds. Rabdomante.

Abal, J.

(2004) La muerte y resurrección de la representación politica. México: FCE.

Aguirre, C. y Mc Evoy, C. (Eds.).

2008 Intelectuales y poder. Ensayos en torno a la república de las letras en el Perú e Hispanoamérica (ss. XVI-XX). Lima: IFEA, Instituto Riva-Agüero, PUCP.

Altamirano, C. (Ed.)

(2010) Los avatares de la ciudad letrada en el siglo XX. Volumen II. Historia de los intelectuales en América Latina. Madrid: Katz Eds.

232

Aragón, J. (Ed.)

2016 Participación, competencia y representación politica. Contribuciones para el debate. Lima: IEP-JNE.

Ayllón, F.

(2019) El diputado Miguel Grau Seminario. Lima: Fondo Ed. del Congreso del Perú. 
Basadre, J.

(1980) Elecciones y centralismo en el Perú. Apuntes para un esquema histórico. Lima: Universidad del Pacífico.

Benito, A. (2017)

El diputado conseguidor: representación política particularista en el Congreso de la República Dominicana (1998-2010). Revista Española de Ciencia Política (44), 151-179.

Bernales, E.

Parlamento y democracia. Lima: Constitución y Sociedad.

Bernales, E.

(2017, 9 de octubre). El Senado es necesario. El Comercio. https:// elcomercio.pe/opinion/columnistas/senado-necesario-enrique-bernales-noticia-464162-noticia/

Casalino, C.

(1991) Diseñando el Perú. José Antonio Encinas y Alberto Ulloa Sotomayor. Pensamiento politico 1945-1947. Lima: CILSE, Senado de la República.

Casalino, C.

Diseñando el Perú. Raúl Porras Barrenechea y Luis Alberto Sánchez. Pensamiento político 1956-1968. Lima: CILSE, Senado de la República.

Casalino, C.

Raúl Porras Barrenechea, Parlamentario. Lima: Ediciones del Congreso del Perú.

Chang-Rodríguez, E.

(2003) Manuel Seoane, páginas escogidas. Lima: Fondo Editorial del Congreso de la República del Perú. 
Chávez, S. y Medrano, U.

(2008) Entrevista al doctor Francisco Eguiguren Praeli. El Parlamento peruano y las funciones del parlamentario: lo que se puede mejorar. Revista Derecho y Sociedad, 31, 15-21.

Contreras, C. y Cueto, M.

(2007) Historia del Perú contemporáneo. Lima: IEP-UP.

Delgado-Guembes, C.

(2011) Para la representación de la República. Apuntes sobre la constitución del Congreso y el estatuto de los parlamentarios. Lima: Fondo Ed. del Congreso del Perú.

Fioravanti, M.

(2011) Constitución. De la Antigüedad a nuestros días. Madrid: Ed. Trotta.

Flores-Zúniga, F.

(2019) Ricardo Palma y la tribuna parlamentaria: el tradicionista senador (1868-1873). Lima: Fondo Ed. del Congreso del Perú.

Gaddis, J.

(2011) Nueva historia de la guerra fría. México: FCE.

Gálvez, J y Ragas, J.

(2010) Tercera parte: Historia. En J. Günter, J. García Bryce y L. Wuffarden, El palacio legislativo. Arquitectura, arte e historia. Lima: Fondo Ed. del Congreso del Perú.

García Montero, M.

(2007) La actividad legislativa en América Latina: sobre el papel reactivo y proactivo de presidentes y parlamentos. Lateinamerika Analysen, 17 (2). 
Gargarella, R.

(2010) Nos los representantes. Critica a los fundamentos del sistema representativo. Buenos Aires: Miño y Dávila Eds.

Guerra Martinière, $M$.

(2016) Manuel Pérez de Tudela: El Republicano. Lima: Fondo Ed. del Congreso de la República, Instituto Riva Agüero, PUCP.

Jiménez, J.

(1994) Las relaciones parlamento-ejecutivo y el sistema legislativo. Lima: PUCP. Pensamiento Constitucional, 1.

Lecaros, $\mathrm{F}$.

(2007) Mario Polar. Ideología y politica socialcristiana. Textos fundamentales. Lima: Fondo Ed. del Congreso de la República.

Llanos, M. y Nolte, D.

(2006) Los congresos en América Latina: legislaturas reactivas, potencialmente activas. Politica, 47, 29-54.

Lossio, J.

(2015) La vida política. En C. Contreras y M. Cueto (Eds.), Mirando hacia dentro, 1930-1960. Barcelona: Taurus. América Latina en la Historia Contemporánea: Perú, t. 4

Lossio, J. y Candela, E.

(2019) Prensa, conspiraciones y elecciones. El Perú en el ocaso del régimen oligárquico. Lima: Instituto Riva-Agüero, PUCP.

Macera, P.

(1999) Presentación. En: Casalino, C. (Comp.) Raúl Porras, parlamentario. Lima: Fondo Ed. del Congreso del Perú. 
Macera, P.

(2020) Parlamento y sociedad en el Perú. Lima: Fondo Ed. Congreso del Perú. 8 vol.

Máiz, R.

(2006) Deliberación e inclusión en la democracia republicana. REIS (6), 11-47.

Manin, B.

(2008) Los principios del gobierno representativo. Madrid: Alianza Ed.

Myers, J. (Ed.)

(2008) La ciudad letrada, de la conquista al modernismo. En C. Altamirano (Dir.), Historia de los intelectuales en América Latina. Madrid: Katz Eds.

Nugent, G.

(2013) José Antonio Encinas. Por la libertad de pensamiento. Discursos parlamentarios. Lima: Fondo Ed. del Congreso del Perú.

Padilla, F.

(2018) El concepto y la representación de lo indio en la propuesta política de Julio César Tello Rojas (1917-1929) (Tesis para optar el grado de magíster en historia). Universidad Nacional Mayor de San Marcos, Lima.

Pease, $\mathrm{H}$. y el 2006. Lima: Fondo Ed. del Congreso del Perú.

Pease, H. y Romero, G.

(2013) La política en el Perú del siglo XX. Lima: PUCP.

Pérez, C. (2015) Liberalismo criollo. Ricardo Palma, ideología y política (1833-1919). Lima: Ed. Universitaria, Universidad Ricardo Palma. 
Poulsen, K.

(2018) ¡Somos ciudadanas! Ciudadanía y sufragio femenino en el Perú. Lima: JNE, PUCP.

Powaski, R.

(2011) La guerra fría. Estados Unidos y la Unión Soviética. 1917-1991. Barcelona: Crítica.

Rebata, R.

(2015)

Elecciones parlamentarias en el Perú (1931-2011). Lima: JNE.

Reynoso, D.

(2010) La diversidad institucional del bicameralismo en América Latina. Perfiles Latinoamericanos, 18 (35), 105-144.

Salmerón, A. M.

(2006) Entre liberalismo y republicanismo. El lugar de la virtud cívica en el ordenamiento social y educativo. Trayectorias, 8(22), 56-65.

Sánchez, F, Nolte, D. y Llanos, M.

(2005) Bicameralismo, senados y senadores en el Cono Sur latinoamericano. Barcelona: Parlament de Catalunya, ICPS.

Santaolalla, F.

(2013) El debate parlamentario y el uso de la palabra. Revista de Derecho Político (86), 47-80.

Schmitt, C.

(2008) Los fundamentos histórico-espirituales del parlamentarismo en su situación actual. España: Tecnos.

Schüttemeyer, S. y Nohlen, D.

(2006) Parlamento. En D. Nohlen, Diccionario de ciencia politica. Teorías, métodos, conceptos. México, D.F.: Ed. Porrúa, El Colegio de Veracruz. 
Thibaut, B.

(2006) Parlamento. En D. Nohlen. Diccionario de ciencia politica. Teorías, métodos, conceptos. México, D.F.: Ed. Porrúa, El Colegio de Veracruz.

Tilly, C.

(2007) Democracia. Madrid: Akal.

Tuesta, F.

(2005) Representación politica: las reglas también cuentan. Sistemas electorales y partidos politicos. Lima: PUCP, Fundación Ebert.

Varillas, A.

(2019) José Gregorio Paredes (1778-1839). Cientifico, politico y creador del escudo nacional. Lima: Fondo Ed. del Congreso del Perú, Instituto Riva Agüero, PUCP.

Villanueva, C.

(2016) Francisco Javier de Luna Pizarro. Parlamentario y primer presidente del Congreso peruano. Lima: Instituto Riva-Agüero, PUCP, Fondo Ed. del Congreso del Perú.

Watanabe, L.

(2017) Federico Villarreal, Senador por Lambayeque. Lima: Fondo Ed. del Congreso del Perú. 